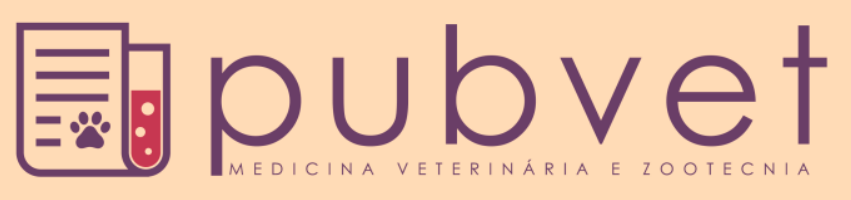

https://doi.org/10.31533/pubvet.v12n9a165.1-7

\title{
Carcinoma de células escamosas em felino: relato de caso
}

\author{
Andréa Maria Carneiro de Melo ${ }^{1 *}$, Thaylana Myrza Saleme $\operatorname{Cardoso}^{2} \bullet$, Maria \\ Vilma Rocha Andrade $\mathrm{Cruz}^{30}$, Cláudia Alessandra Alves de Oliveira ${ }^{3}{ }^{\bullet}$, Kelly \\ Cunha Vital ${ }^{1}$, Rafaela Maria Pastl ${ }^{10}$, Kézia dos Santos Carvalho ${ }^{30}$
}

${ }^{I}$ Médica Veterinária autônoma, Maceió, AL.

${ }^{2}$ Graduanda do Curso de Medicina Veterinária do Centro Universitário Cesmac, Maceió, AL.

${ }^{3}$ Médica Veterinária e Mestre do Centro Universitário Cesmac, Maceió, AL

*Autor para correspondência,E-mail: andreac.melo@uol.com.br

RESUMO. O carcinoma de células escamosas é uma neoplasia maligna que surge a partir das células do epitélio escamoso, consistindo no tipo mais comum de tumor de pele em felinos, onde a radiação solar é o fator contributivo nos gatos de pele clara ou despigmentada. Objetivou-se com este trabalho relatar um caso de carcinoma de células escamosas descrevendo os aspectos clínicos e patológicos envolvidos na doença em uma gata sem raça definida, com aproximadamente 12 anos, apresentando lesão ulcerativa bilateral no plano nasal, que foi atendida na Clínica Escola de Medicina Veterinária do Centro Universitário Cesmac, Maceió, AL, Brasil. Os sinais clínicos observados foram epistaxe, dificuldades respiratórias e conjuntivite crônica. Os achados citológicos foram compatíveis com granuloma eosinofílico. Foi instituído tratamento terapêutico com acetato de metilpredinisolona, no entanto, o animal não apresentou melhora após o tratamento, diante disso, sugere-se que o carcinoma foi mascarado pela reação inflamatória, ou ainda, que o granuloma tenha promovido o carcinoma. O diagnóstico precoce foi importante para o prognóstico e melhor avaliação dos fatores predisponentes do carcinoma de células escamosas em felinos.

Palavras chave: Neoplasia, felinos, granuloma eosinofílico, cancer

\section{Squamous cells carcinoma in feline: case report}

\begin{abstract}
Squamous cell carcinoma is a malignant neoplasm arising from cells of the squamous epithelium, consisting of the most common type of skin tumor in felines, where solar radiation is the contributory factor in cats with light or depigmented skin. The objective of this work was to report a case of squamous cell carcinoma describing the clinical and pathological aspects involved in the disease in a cat with no defined breed, approximately 12 years old, presenting bilateral ulcerative lesion in the nasal plane, which was attended at the Clínica Escola de Veterinary Medicine, Centro Universitário Cesmac, Maceió, AL, Brazil. The clinical signs observed were epistaxis, respiratory difficulties and chronic conjunctivitis. Cytological findings were compatible with eosinophilic granuloma. Therapeutic treatment with methylpredinisolone acetate was instituted, however, the animal did not show improvement after the treatment, on the contrary, it is suggested that the carcinoma was masked by the inflammatory reaction, or that the granuloma promoted the carcinoma. Early diagnosis was important for a prognosis and better evaluation of the predisposing factors of squamous cell carcinoma in felines.
\end{abstract}

Keywords: Neoplasia, cats, eosinophilic granuloma, cancer 


\section{Carcinoma de células escamosas en felino: reporte de un caso}

RESUMEN. El carcinoma de células escamosas es una neoplasia maligna que surge a partir de las células del epitelio escamoso, consistente en el tipo más común de tumor de piel en felinos, donde la radiación solar es el factor contributivo en los gatos de piel clara o despigmentada. Se objetivó con este trabajo relatar un caso de carcinoma de células escamosas describiendo los aspectos clínicos y patológicos involucrados en la enfermedad en una gata criolla, con aproximadamente 12 años, presentando lesión ulcerativa bilateral en el plano nasal, que fue atendida en la Clínica Escuela de Medicina Veterinaria del Centro Universitario Cesmac, Maceió, AL, Brasil. Los signos clínicos observados fueron epistaxis, dificultades respiratorias y conjuntivitis crónica. Los hallazgos citológicos fueron compatibles con granuloma eosinofílico. Se estableció tratamiento terapéutico con acetato de metilpredinisolona, sin embargo, el animal no presentó mejoría después del tratamiento, ante ello, se sugiere que el carcinoma fue enmascarado por la reacción inflamatoria, o aún, que el granuloma haya promovido el carcinoma. El diagnóstico precoz fue importante para o pronóstico y una mejor evaluación de los factores predisponentes del carcinoma de células escamosas em felinos.

Palabras clave: Neoplasia, felinos, granuloma eosinofílico, carcinoma

\section{Introdução}

A pele e os tecidos moles são dois grandes alvos de surgimento de neoformações nos animais domésticos, talvez, pela variedade de tipos celulares potencialmente capazes de se transformar em neoplasia (Jones et al., 2000). Existem variedades de doenças neoplásicas, sendo que nenhuma possui origem única, são provenientes de causas variadas. Dessa forma, o estudo das neoplasias é de fundamental importância para a compreensão de suas causas, tipos e formas de tratamento. Segundo Dias et al. (2015), as neoplasias da pele e seus anexos são bastante comuns em países de clima tropical, como o Brasil, devido à exposição crônica dos animais à radiação ultravioleta. $\mathrm{O}$ carcinoma de células escamosas (CCE) é uma neoplasia maligna que surge a partir das células do epitélio escamoso, consistindo no tipo mais comum de tumor de pele em felinos (Sherding, 1994; White, 2003).

A lesão inicial de CCE pode estar presente por meses ou anos, onde a história clínica está associada a um ferimento que não cicatriza. Nos CCE associados à luz solar, os sinais podem progredir vagarosamente ou crescer e diminuir por meses (Rosolem et al., 2012). A forma cutânea do CCE, em felinos, geralmente, localiza-se na cabeça, especialmente em áreas pouco pigmentadas e desprovidas de pelos (região glabra), como as orelhas, plano nasal, lábios e pálpebras (Goldschmidt \& Shofer, 1992; Meuten, 2002; White, 2003). Possui comportamento agressivo, sendo extremamente invasivo e podendo provocar deformação facial nos gatos acometidos (Chandler et al., 2006; Meuten, 2002; Miller et al., 2013). A etiologia é desconhecida, como ocorre na maioria das neoplasias, entretanto alguns autores sugerem que a causa exógena mais comumente aceita para esta neoplasia é a exposição à luz ultravioleta (Collins et al., 2000; Ettinger \& Feldman, 2004). Encontrados mais em gatos brancos, de olhos azuis e pele hipopigmentada (Gross et al., 2008; Guedes et al., 1998).Os animais afetados, na maioria das vezes, apresentam idade avançada e gatos domésticos SRD de pelame claro são mais predispostos quando comparados aos de pelame escuro (Stannard \& Pulley, 1978; Withrow et al., 2014.

O tratamento pode ser por meio de cirurgia, radioterapia, criocirurgia, terapia fotodinâmica ou quimioterapia tópica (Ettinger \& Feldman, 2004; Ferreira et al., 2006; Goldschmidt \& Hendrick, 2008; Lucas \& Larsson, 2006; Raskin \& Meyer, 2003). Tratamentos cirúrgicos e crioterápicos são mais escolhidos, pois o CCE possui baixa capacidade metastática (Barros \& Repetti, 2015; Fontes et al., 2008).

A eletroquimioterapia vem ganhando destaque na medicina veterinária. Sua utilização visa aumentar a eficácia de quimioterápicos aumentando sua absorção dentro das células tumorais através da administração de pulsos elétricos permeabilizantes (Spugnini \& Baldi, 2014).

Uma outra forma, é a imunoterapia ativa, a estimulação inespecífica do sistema imune com a ajuda da micobactéria Calmette-Guerin (BCG). A 
BCG é introduzida no hospedeiro na região de crescimento do tumor no intuito de ativar os macrófagos e, consequentemente, destruir as células tumorais (Logan et al., 2005).

O diagnóstico de CCE inicia-se com histórico, anamnese e exame físico completo, evidenciando os sinais clínicos e fatores predisponentes característicos da neoplasia (Ettinger \& Feldman, 2004; Meuten, 2002; Sherding, 1994). O diagnóstico definitivo só poderá ser obtido pelo exame histopatológico (Cumming \& Semple, 1980). O exame histopatológico é a principal ferramenta para confirmação do diagnóstico dessa doença oncológica, por possuir uma boa especificidade e baixo custo, exame citológico da lesão neoplásica por técnica de impressão ou punção aspirativa por agulha fina também pode ser de auxílio diagnóstico, porém a melhor técnica para diagnóstico definitivo é a biópsia excisional (Cumming \& Semple, 1980; Wolf, 1996). Quando a histopatologia é inconclusiva devem ser aplicadas técnicas de imuno-histoquímica (Gross et al., 2008). Em concordância com Ferreira et al. (2006), o diagnóstico precoce é importante, pois lesões pequenas podem ser erradicadas. O controle do tumor primário, independentemente do tamanho no momento do diagnóstico, é um fator importante para melhorar o tempo de sobrevivência, e, consequentemente, o tratamento de metástases pode ser importante nos casos em que o controle em longo prazo do tumor primário é possível (Soltero-Rivera et al., 2014).

Como diagnósticos diferenciais de CCE incluem-se as neoplasias: epitelioma cornificado intracutâneo, papiloma escamoso, carcinoma basoescamoso melanoma, mastocitoma, hemangioma ou hemangiossarcoma cutâneo, tumores do folículo piloso e ainda dermatofitose, pênfigo e processos alérgicos como o granuloma eosinofílico. (Raskin \& Meyer, 2003), É fundamental realizar o diagnóstico diferencial, pois apresentam formas de tratamentos diferenciadas (Norsworthy et al., 2004). O prognóstico é mau para gatos com tumores invasivos e indiferenciados. Animais com tumores minimamente invasivos, com menos de $2 \mathrm{~cm}$ de diâmetro recebem melhor prognóstico (Norsworthy et al., 2004). A prevenção é restringir o animal a exposição solar (Rosa et al., 2006).

Este trabalho tem como objetivo relatar os aspectos clínicos e patológicos envolvidos no carcinoma de células escamosas em uma felina doméstica.

\section{Relato de Caso}

Foi atendida na Clínica Escola de Medicina Veterinária, do Centro Universitário Cesmac, uma felina, SRD, com aproximadamente 12 anos de idade, castrada, não vacinada, de pelagem branca, pesando $3,5 \mathrm{~kg}$, apresentando lesão ulcerativa bilateral no plano nasal há aproximadamente 5 meses (Figura 1).

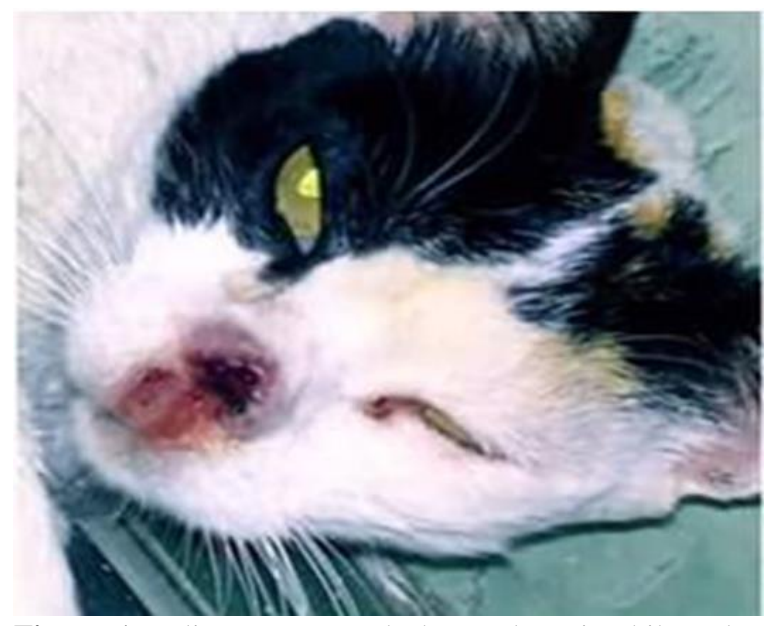

Figura 1. Felina apresentando lesão ulcerativa bilateral no plano nasal.

$\mathrm{Na}$ anamnese foi relatado que a felina era de origem errante. No exame clínico, constatou-se linfonodos mandibulares aumentados, mucosas pálidas, turgor da pele diminuído. Os parâmetros fisiológicos como temperatura, frequência cardíaca e respiratória, além do tempo de perfusão capilar, encontravam-se dentro dos valores de referência.

Os sinais clínicos observados foram epistaxe, dificuldades respiratórias, ulceração do plano nasal, e conjuntivite crônica.

Após o exame clínico foi feito colheita de amostra sanguínea para hemograma e bioquímica sérica (AST, ALT, Ureia, Creatinina, Fosfatase alcalina, Albumina e GGT), além de punção por agulha fina (PAAF) de amostra para análise citológica. As amostras foram encaminhadas para os laboratórios de Análises Clínicas e Histopatologia, respectivamente. Não foram encontradas alterações significativas no hemograma e funções bioquímicas solicitadas relacionadas com o carcinoma e os achados citológicos foram compatíveis de granuloma eosinofílico, onde foi instituído o tratamento clínico com acetato de metilpredinisolona, no entanto a gata não apresentou melhora após o tratamento. Este animal foi submetido ainda a exame sorológico para detecção do vírus da 
imunodeficiência felina (FIV) e para o vírus da leucemia felina (FELV), utilizando-se de um teste rápido, Alere ${ }^{\circledR}$, e o mesmo apresentou-se positivo para FELV.

Seguido a falta de resposta ao tratamento para o granuloma eosinofílico foi realizado biópsia da lesão nasal para análise histopatológica.

A amostra coletada após fixação em formol a $10 \%$ foi submetida a processamento histológico rotineiro, submetidos a etapa de desidratação em concentrações crescentes de álcool $(70 \%, 80 \%$, $90 \%$ e $100 \%$ ), seguido por um processo de clarificação com xilol $(1,11)$. Em seguida foi incluído em parafina. $\mathrm{O}$ material processado foi cortado em micrótomo calibrado para cortes de $5 \mu$ e coradas pela técnica de hematoxilina-eosina, e por fim foram analisadas em microscópio óptico.

$\mathrm{Na}$ microscopia foi observada massa neoplásica caracterizada por formação de ninhos de células escamosas, com formação de pérolas de queratina no centro de vários ninhos (Figura 2), a célula caracteriza-se por núcleo arredondado, basofílico, nucléolo central e proeminente, citoplasma anfofílico e escasso. Estroma discreto e infiltrado inflamatório linfoplasmocitário foi também observado, compatível com carcinoma de células escamosas, além de outros achados secundários de hiperqueratose associado a colônias bacteriana (Figura 3). Estes achados da análise histopatológica foram sugestivos de carcinoma de células escamosas.

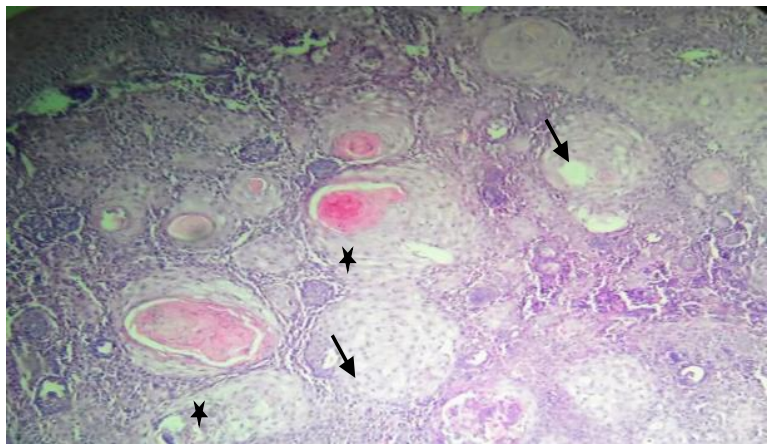

Figura 2. Observa-se massas de células neoplásicas formado por ilhas de células escamosas (asterisco) com formação de pérolas de queratina (seta).

O animal apresentou prognóstico desfavorável, por apresentar outros agravantes no quadro clínico, manifestando mau estado geral, seguida a falta de resposta, apesar de se prover de condições de suporte, não evoluiu bem, sendo submetido à eutanásia e o cadáver foi encaminhado para necropsia e coleta de material para exame histopatológico.

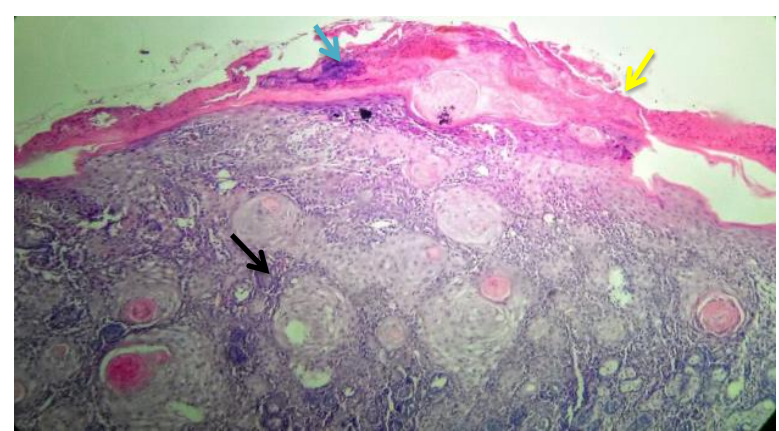

Figura 3. Observa-se ilhas de células escamosas circundadas por moderado. Inflamatório $(\rightarrow)$, hiperqueratose $(\rightarrow)$ associados a colônias bacterianas. $(\rightarrow)$.

\section{Discussão}

O CCE é uma neoplasia formada a partir das células da epiderme e corresponde a uma neoformação maligna dos queratinócitos que podem apresentar crescimento lento e não necessariamente metastático, comum em felinos, bovinos, caninos, equinos, incomum em ovinos e raros em caprinos e suínos (Dias et al., 2015; Goldschmidt \& Hendrick, 2002; Goldschmidt \& Hendrick, 2008).

Ferreira et al. (2006) comentam que em alguns casos há uma associação entre FELV e FIV com o CCE em felinos, onde a imunossupressão decorrente da ação viral impede o hospedeiro de produzir resposta humoral e celular frente à neoplasia e, consequentemente possibilitando o crescimento tumoral, neste caso, é possível ter ocorrido este evento, uma vez que o animal apresentou uma evolução clínica progressiva rápida e incompatível com as características anatomopatológicas do tumor. Segundo Munday et al. (2009), o vírus da imunodeficiência felina (FIV) e os papilomavírus também podem causar imunossupressão e uma alta incidência de CCE, são capazes de infectar células do epitélio, mas não fornecem provas do seu envolvimento no crescimento de CCE de felinos. Sendo necessários estudos complementares para determinar se estes vírus causam a doença em gatos ou são invasores secundários de epitélios com células anormais. As análises hematológicas e bioquímicas não são úteis para o diagnóstico do CCE, mas são indicadas para avaliar a condição geral do paciente.

O exame citológico foi sugestivo de granuloma eosinofílico, diante deste achado, sugere-se que possivelmente $o$ animal apresentava reações concomitantes e que o carcinoma ficou mascarado pela reação inflamatória ou ainda pode-se supor que o granuloma tenha sido uma lesão promotora do carcinoma, como argumenta Daleck et al. 
(2016) ao ressaltar que a exposição crônica aos raios ultravioletas não corresponde à única forma de desenvolvimento do CCE, existindo ainda outros fatores como infecções por papilomavírus e infecções crônicas, como causas primárias para o surgimento do CCE, sendo neste caso o granuloma um causador iniciante e promotor do CCE e ainda considerando a presença positiva para FELV.

Segundo Miller et al. (2013) existem dois tipos clínicos de CCE. Um que se manifesta por lesões proliferativas e outra por lesões erosivas (ulcerativas). O CCE proliferativo caracteriza-se por lesões de diversos tamanhos, podendo variar desde placas firmes e avermelhadas a massas papilares de vários tamanhos, a maioria com aparência de couve-flor, sangra facilmente e encontra-se ulcerada.

As lesões características do tipo ulcerativo inicialmente se apresentam superficiais, crostosas ou ulceradas e com o tempo ficam profundas e crateriformes. O seu tamanho também é variável. As lesões erosivas são as que estão mais frequentemente associadas à exposição crônica à radiação ultravioleta, remete a uma relação com as condições de vida do animal que era errante e exposto aos interpérios do tempo (sol) e as características morfológicas do animal do caso. Os padrões macroscópicos são eritema, úlcera, placa e aumento de volume. Este padrão ulcerativo foi compatível com as características clínicas encontradas no animal do relato (Daleck et al., 2016). Como observado em literaturas consultadas, os gatos brancos são mais predispostos a apresentar esse tipo de tumor (Ruslander et al., 1997). O local da lesão condiz com o que foi visto na literatura (Meuten, 2016).

As alterações sistêmicas que induziram o agravamento do quadro clínico foram progressivas, resultando em um prognóstico desfavorável, fato que embasou a decisão pela eutanásia, a evolução clínica foi sugerida pelos achados morfopatológicos, caracterizados por necrose hepática, edema e congestão pulmonar e ainda nefrite intersticial.

\section{Considerações Finais}

O acompanhamento do presente caso possibilitou uma análise da evolução das manifestações clínicas do carcinoma de células escamosas em felinos, permitindo relacionar as diferentes e possíveis patologias do animal em estudo.
Ressaltando ainda a importância do diagnóstico precoce para melhor resposta prognóstica e melhor avaliação dos fatores predisponentes a ocorrência de CCE em felinos.

\section{Referências Bibliográficas}

Barros, V. T. M., \& Repetti, C. S. F. 2015. Metronomic chemotherapy in dogs: a review. Revista Portuguesa de Ciência Veterinárias, 110, 593-594.

Chandler, E. A., Gaskell, C. J., \& Gaskell, R. M. 2006. Clínica e terapêutica em felinos. São Paulo: Editora Roca.

Collins, T., Cotran, R. S., \& Kumar, V. 2000. Patologia estrutural e funcional. Rio de Janeiro, Brasil: Guanabara, Koogan.

Cumming, G., \& Semple, S. J. 1980. Disorders of the respiratory system.

Daleck, C. R., Fonseca, C. S., \& Canola, J. C. 2016). Oncologia em cães e gatos. Rio de Janeiro: Roca.

Dias, F., Dias, L., Pereira, L., Cabrini, T., \& Rocha, J. 2015. Neoplasias orais nos animais de companhia-Revisão de literatura. Revista Científica Eletrônica de Medicina Veterinária, 20(1), 1-9.

Ettinger, S., \& Feldman, E. 2004. Tratado de medicina interna veterinária: doenças do cão e do gato. Rio de Janeiro: Guanabara Koogan.

Ferreira, I., Rahal, S. C., Ferreira, J., \& Corrêa, T. P. 2006. Terapêutica no carcinoma de células escamosas cutâneo em gatos. Ciência Rural, 36(3), 1027-1033.

Fontes, K. B. F. C., Milagres, A., Piragibe, M. M. M., Silva, L. E., \& Dias, E. P. 2008. Contribuição da citopatologia para $O$ diagnósticode carcinoma de célula

Shmitt, I., \& LuisPippi, N. 1998. Dermati s escamosas oral. Jornal Brasileiro de Patologia e Medicina Laboratorial, 44(1), 17-24.

Goldschmidt, M. H., \& Hendrick, M. J. 2002. Tumors of the skin and soft tissues. In D. J. Meuten (Ed.), Tumors in domestic animals (pp. 45-117). Iowa, USA: Iowa State Press.

Goldschmidt, M. H., \& Hendrick, M. J. 2008. Tumors of the skin and soft tissues. In D. J. Meuten (Ed.), Tumors in Domestic Animals, Fourth Edition (pp. 45-117). Iowa: Iowa State Press.

Goldschmidt, M. H., \& Shofer, F. S. 1992. Skin tumors of the dog and cat. Oxford: Pergamon Press Ltd. 
Gross, T. L., Ihrke, P. J., Walder, E. J., \& Affolter, V. K. 2008. Skin diseases of the dog and cat: clinical and histopathologic diagnosis. Oxford: John Wiley \& Sons.

Guedes, A. G. P., Uedes, A. G. P., Shmitt, I. \& Pippi, N. L. 1998. Dermatite solar felina associada a carcinoma epidermóide. Ciência Rural, 28(4), 707-713.

Jones, T. C., D., H. R., \& King, N. W. 2000. Patologia veterinária. São Paulo, Brasil: Manole.

Logan, K. E., Chambers, M. A., Hewinson, R. G., \& Hogarth, P. J. 2005. Frequency of IFN- $\gamma$ producing cells correlates with adjuvant enhancement of bacille Calmette-Guèrin induced protection against Mycobacterium bovis. Vaccine, 23(48-49), 5526-5532.

Lucas, R., \& Larsson, C. E. 2006. Crioterapia na clínica veterinária: avaliação da praticabilidade, e efetividade em carcinoma espinocelular de felinos. Brazilian Journal of Veterinary Research and Animal Science, 43(Supl.), 33-42.

Meuten, D. J. 2002. Tumors of the skin and soft tissues. Iowa: Iowa Satate Press.

Meuten, D. J. 2016. Tumors in domestic animals: John Wiley \& Sons.

Miller, W. H., Griffin, C. E., Campbell, K. L., \& Muller, G. H. 2013. Muller and Kirk's Small Animal Dermatology. Philadelphia, USA: Elsevier Health Sciences.

Munday, J. S., Howe, L., French, A., Squires, R. A., \& Sugiarto, H. 2009. Detection of papillomaviral DNA sequences in a feline oral squamous cell carcinoma. Research Veterinary Science, 86(2), 359-361.

Norsworthy, G. D., Crystal, M. A., Grace, S. F., \& Tilley, L. P. 2004. O paciente felino. São Paulo: Roca, 3, 300.

Parreira, I. M., \& Keglevich, E. 2005. As neoplasias em cães. Enciclopédia Biosfera, 1, 1-32.

Raskin, R. E., \& Meyer, D. J. C. 2003. Atlas de citologia de cães e gatos. São Paulo, Brasil: Roca.

Rosa, C. S., Martins, A. A., Santin, R., Faria, R. O., Nobre, M. O., Meireles, M. C. A., Nascente, P. S. 2006. Malassezia pachydermatis no tegumento cutâneo e meato acústico externo de felinos hígidos, otopatas e dermatopatas, no município de Pelotas, RS, Brasil. Acta Scientiae Veterinariae, 34(2), 143147.

Rosolem, M. C., Moroz, L. R., \& Rodigheri, S. M. 2012. Carcinoma de células escamosas em cães e gatos: Revisão de literatura. PUBVET, 6, Art. 1295-1300.

Ruslander, D., KaserHotz, B., \& Sardinas, J. C. 1997. Cutaneous squamous cell carcinoma in cats. Compendium on Continuing Education for the Practicing Veterinarian, 19(10), 1119-1129.

Sherding, R. G. 1994. The cat: diseases and clinical management.

Soltero-Rivera, M. M., Krick, E. L., Reiter, A. M., Brown, D. C., \& Lewis, J. R. 2014. Prevalence of regional and distant metastasis in cats with advanced oral squamous cell carcinoma: 49 cases (2005-2011). Journal of Feline Medicine and Surgery, 16(2), 164-169.

Spugnini, E. P., \& Baldi, A. 2014. Electrochemotherapy in veterinary oncology: from rescue to first line therapy. Methods Molecular Biology, 1121, 247-256.

Stannard, A. A., \& Pulley, L. T. 1978. Tumors of the skin and soft tissues. In J. E. Moulton (Ed.), Tumors in domestic animals (pp. 211-212). Los Angeles, USA: University of California Press.

White, R. A. S. M. C. T. I. D., J.M.; Lacelles, D. D. $X$. BSAVA:Manual of canine an feline oncology. Gloucester: BSAVA, p.161-167, 2003. 2003. Mast cell tumors. In J. M. Dobson \& D. D. X. Lacelles (Eds.), Manual of canine an feline oncology (pp. 161-167). Gloucester: BSAVA.

Withrow, S. J., Page, R., \& Vail, D. M. 2014. Ssmall animal clinical oncology. St. Louis: Elsevier Health Sciences.

Wolf, A. M. 1996. Moléstias da cavidade nasal e seios paranasais. In M. J. Bojrad (Ed.), Mecanismos da moléstia na cirurgia dos pequenos animais (Vol. 2, pp. 423-431). São Paulo, Brasil: Manole.

Recebido: 26 Jun. 2018 Aprovado: 14 Jul. 2018

Publicado: 16 Ago. 2018

Licenciamento: Este artigo é publicado na modalidade Acesso Aberto sob a licença Creative Commons Atribuição 4.0 (CC-BY 4.0), a qual permite uso irrestrito, distribuição, reprodução em qualquer meio, desde que o autor e a fonte sejam devidamente creditados. 